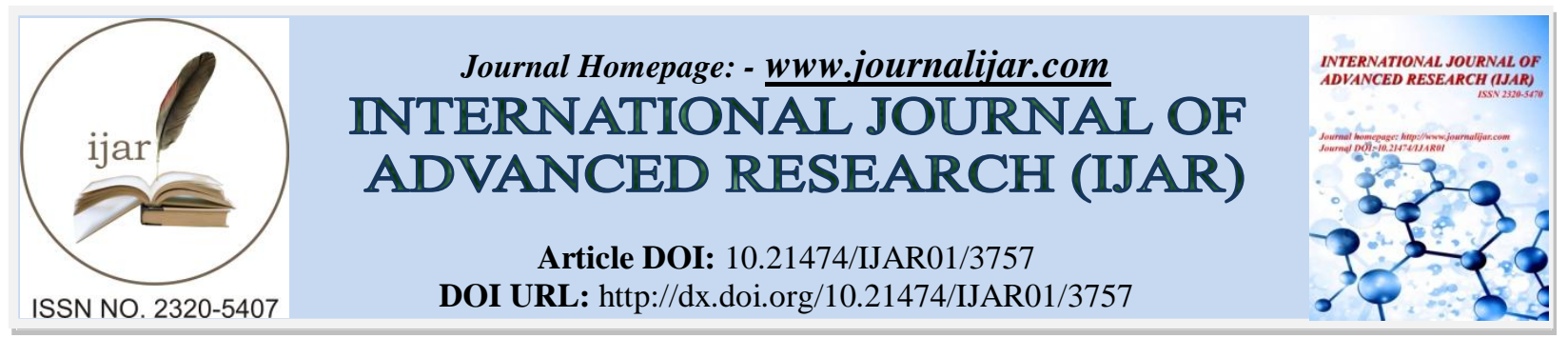

RESEARCH ARTICLE

\title{
THE MAIN RESOURCES OF DIVERSITY AND ITS EFFECTS ON THE QUALITY OF WORK LIFE OF HUMAN RESOURCES.
}

Aysar khashman, Abdelmutti Assaf, Feras Alzubi and Ayyoub alsawalhah.

Department of Management, Faculty of Finance and Business Administration, the World Islamic Sciences \& Education University, Jordan.

\section{Manuscript Info}

Manuscript History

Received: 16 January 2017

Final Accepted: 12 February 2017

Published: March 2017

Key words:-

Diversity, Quality of Work Life.

\section{Abstract}

This study aimed at Identifying the impact of the case of functional diversity on the quality of work in the surveyed organization system, and the impact of diversity by gender, diversity by age, Diversity by specialization, and diversity, according to the functional level the stuff on the quality of work in surveyed organization. The study concluded that there is high impact for these variables on the quality of work. It recommends that the bank strategy should take in consideration the unity and balance of the organization, and carry out the requirements of its integration.

Copy Right, IJAR, 2017,. All rights reserved.

\section{Introduction:-}

All organizations, of all kinds, whether governmental organizations or business organizations or civil society organizations ...., in different sectors of work, if it is agricultural organizations, industrial or service ...it is working hard to be a unified and balanced organizations, so that it meets all components of each organization, and interact together to form a (system)to be integrated and balanced, so it looked like a human body that if one part was suffering all body will be suffering and felt the pain too . The human element is the base for this Organization unity, it is the only vital element in the organization, which gives it's a vitality and governs it's movement, in it the organization life cycle begins to take shape, and finishes when it's finish. Thus, it should develop an integrated strategy for the management of human resources, to effectively manage the organization to achieve balance and united desired. Multiple components that play in any integrated strategy, but the demand to manage the diversity of human resources and the understanding of its effects on the unity of the organization and the elements of its balance, is one of the key components of this strategy. It demands to build a system for the quality of working life and is a major part in it. And that this study will revolve around these two variables, with a focus on the impact of the case of functional diversity on the quality of working life in the Jordan Islamic Bank.

\section{He problem of the study:-}

Contemporary organizations concerned with the requirement to build an advanced system to improve the quality of life work, has also become interested in the phenomenon of functional diversity as one of the main variables that affect the lives of organizations, and that the problem of this study centered on the search this matter to answer the following question: 
Is the case of functional diversity affect the quality of working life of the system in the Jordan Islamic Bank. The importance of the study:-

The importance of the study from a scientific point that it's working on a research influential relationship between two variables and they are considered the most important variables that are keen various of the organizations on their management to manage it effectively, due to their uncertain role in preserving the unity, integrity and balance of organizations. They also have practical importance where the results of it will help the specialized departments, in particular, the human resources management in the surveyed organization to develop strategies in a more rational and effective.

\section{Objectives of the study:-}

The main objective in the study is the impact of the case of functional diversity on the quality of work in the surveyed organization system. The ramifications of the following sub-goals:

- Knowledge of the impact of diversity by gender on the quality of work in surveyed organization.

- Knowledge of the impact of diversity by age on the quality of work in the surveyed organization.

- Knowledge of the effect of diversity, according to specialization on the quality of work in surveyed organization.

- Knowledge the effect of diversity, according to the functional level the stuff on the quality of work in surveyed organization.

\section{Study model: based on two variables:-}

The independent variable: the diversity of human resources, and the ramifications of several sub-variants, have been some of the sub variables is appropriate exception to the case of the Islamic bank because there is no diversity of this kind, and that as a variable of race or nationality or values, emphasis was placed on four variables are: (diversity by gender, by age, according to the categories of staff (administrators and executives) and according to the functional level (senior management, central and lower). The dependent variable: the quality of working life of the system, and the ramifications sub-variables (working conditions, labor problems, and the system of security and public safety). Source: prepared by the researcher, based on (Sail \& Alavi, 2010), (Sing, 2011), (Dessler, 2004) (Assaf, 2012).

\section{Hypotheses:-}

\section{The main hypothesis (H01):-}

No effect is statistically significant at a moral level $(\mathrm{P} \leq 0.05)$ for the cases of diversity in human resources in terms of its scopes (gender, age and categories of employees, career level), the quality of work life of the system in terms of its scopes (the conditions of the physical work and the problems of work and the system of security and safety) in the Jordan Islamic Bank.

\section{Sub-hypotheses:-}

$>$ The first hypothesis (H01-1): No effect is statistically significant at a moral level $(\mathrm{P} \leq 0.05)$ for diversity by gender, the quality of work life of the system in terms of its scopes (physical working conditions and labor problems and the system of security and safety) in the Jordan Islamic Bank.

$>$ The second hypothesis (H01-2): No effect is statistically significant at a moral level $(\mathrm{P} \leq 0.05)$ for diversity by age, the quality of work life of the system in terms of its scopes (physical working conditions and labor problems and the system of security and safety) in the Jordan Islamic Bank.

$>$ The third hypothesis (H01-3): No effect is statistically significant at moral level $(\mathrm{P} \leq 0.05)$ diversity, according to specialization, the quality of work life of the system in terms of its scopes (physical working conditions and labor problems and the system of security and safety) in the Jordan Islamic Bank.

$>$ hypothesis fourth (H01-4): No effect is statistically significant at a moral level $(\mathrm{P} \leq 0.05)$ diversity, according to the functional level, the quality of work life of the system in terms of its scopes (the conditions of the physical work and the problems of work and the system of security and safety) in the Jordan Islamic Bank.

\section{Methodology of the study:-}

$>$ The study relies on two approaches descriptive and analytical, a case study of the Jordan Islamic Bank. The study includes managers of the bank's branches in Amman community, which is numbering 30 branches, and the study included a survey of all levels of society.

$>$ Questionnaire was designed for the purposes of this study, it has been distributed to all members of the sample, and 24 forms were obtained from the numbers, which was $80 \%$. Also Likert scale has been used; it was an appropriate statistical analysis to test the hypotheses of the study. 


\section{Literature:- \\ Managing the diversity in human Resources:-}

All organizations, of whatever type, is working hard to be a unified and balanced organizations, to integrate all the components of each organization, and interact together to form both the (system) integrated and balanced. (Kehinde,2012). The human element in any organization considered the single vital element which gives it vitality and governs its movement. As the human resources by nature is characterized by diversity and difference, its presence within any organization will ask an important question about the impact of this diversity or differences on the unity of the organization and the elements of balance, and the performance and effectiveness levels, and this is what forces the organizations to take the necessary degree of attention, and to include it within their strategies. (Noori,2013). Have multiple definitions offered by scholars of the concept of diversity despite the clarity of the concept which is inherently in it, it does not provoke any controversy around the researchers to try to clarify the truth, diversity is the variety and differences in the types of human resources, and its degree, according to each organization and what are the sources that they get their human resources, and we do not have to define the axioms. The distinct and more voluminous organizations and geographical spread, especially cross-border and multi-national organizations, the more diversity is more apparent, it has helped the phenomenon of globalization, and the phenomenon of complexity and entanglement in international economic and political relations, the proliferation of such organizations. (Richard,2008) (Nasyira,Othman,\&Gazali,H ,2014).

\section{Cases of the diversity of human Resources:-}

First, the diversity of gender ; this has become a source of the most common causes of diversity in various organizations, without exception, even the military and security ones, as a result of the expansion of the entry of women into the work field, and markedly and growing, due mostly to: (Polk,2011,167),( Suhasini\&, Naresh, 2013).

$>$ The growth of public awareness of the heads of families in different communities, especially in Arab societies, as a result of the spread of education among them, the need to give girls opportunities in education, in response to the imperatives of social life on the one hand, and the evolution of consciousness and religious understanding, which focuses on the importance of girls' education.

$>$ The general sense of the growth of the necessity of equality between men and women, especially in front of education and employment opportunities, has become the general legislation in most states which imposed it. International pressure operated global trend organizations which they have supported it.

$>$ The pressure of economic life, and the weight of the economic burden on many families, prompting the woman to go and female heads of households and their daughters to enter the practical life to help men to provide the growing needs of the family members.

There is no doubt that the differences are organic and differences between males and females are differences (Congenital), are present at the origin of the creation of all of them and that it has direct effects and remark on their behavior in public life and working life, and that is necessary for each organization to put these differences into account, and what is most important can be referred to as: (Zikmund,2000,54), ( Ichi, , \&Arthur, 1984,68-74)

- distinguish between jobs that require physical efforts and capabilities, and guide the male workers to it because they are characterized as having high capabilities more than females in this area.

- recognize the high degree of emotional transparency among females than males, and by taking into account the situation of women and not to put her in a decision-making positions, which are constantly under pressure from the centers of power in the organization or community. If it is necessary to put women in certain positions of leadership, it is important to have a number of male advisers who are able to support in any situation like this.

- Note some of the characteristics that can be characterized by the female often, that they do things in details, and have ordinal and protocol capabilities, and so on, so you can take advantage of the functions or activities that they do.

Second, the diversity of culture; where is the culture in the organization is the most important factors that affect the unity and balance of the organization, if the organization has a clear and unified culture, and workers with different functional levels stick to it, and to be organized at their best, then it will be cohesion and balanced. But if there were cultural differences among workers, and is rooted in their consciousness, and visible in practice, this is one of the most dangerous things that can be faced by the organization, and inevitably leads to disagreements and conflicts that threaten the unity of the organization and perhaps its existence as well. (Chuai, 2008). The concept of the culture is important, which needs to clarify and be determined, when we follow up on the most important definitions provided, 
we can offer an integrated definition which defines culture as the outcome of three basic systems of interaction : (Assaf, 2012,265):

$>$ System prevailing values

$>$ System prevailing public knowledge

$>$ The skills and expertise which include customs, traditions and tools, rituals and symbols and techniques and means. that prevail in the life of the community or organization system.

Cultural diversity challenge in most international organizations has become a reality case, where these organizations are spread and have hundreds of branches around the world, and attracts thousands upon thousands of workers from different cultures, and this is what is in fact the most important factors that should be on the public authorities of any such organization, be taken into account, and that the design is suitable to make a bigger deal of cultural integration, and the development of the spirit of citizenship functional strategies, and without it threatening the unity of the organization, and more likely failures. (Drucker, 1998,165-172).

Third, the diversity of nationalities; due to global openness among many regional organizations or cross-border, as well as the many local organizations in some countries that rely on imported labor from abroad, as in the case of the Gulf countries, and some other oil states like Libya and Algeria. As it happens for most major industrial countries, which amounted to the degree of expansion of their organizations to import manpower from abroad. The diversity of nationalities represents one of the main sources of cultural diversity in many cases; in addition to that it may represent a source of some of the conflicts that may arise as a result of the existence of political sensitivities, economic or ... between some of the countries to which it belongs. The organizations that are monitoring these cases and practices, and put suitable strategies to manage this diversity and overcome the disadvantages, and take advantage of it to greater vitality to its life and operations.

Fourth:- The diversity of races and colors; in turn its reflected in the cultural diversity on the one hand, it also represents one of the major factors of difference and disagreement, and perhaps conflict within organizations, especially if it has been associated with the multiplicity of nationalities, or social and political sensitivities. That the organizations be aware of the truth of this matter, and take him into consideration which put its strategies to build a united and balance.

Fifth:- The religious and sectarian diversity; and it is considered the most dangerous sources and the most important events in the cultural diversity, and it set on the flame of the rivalry between the workers and to the degree it may sometimes be devastating. It is true that organizations can paint a functional policy which abolish the status of religions and sects, but it is important to give it a constant attention, and concern for the lack of full openness to diverse sources of religiously and ideologically as much as possible, because in the case where the religious and sectarian rivalry, if happened it will become out of control, and difficult to be contained, and it threatens the life of organizations actually.

Sixth:- The diversity of ages; the wide gap between the ages of workers in any organization lead undoubtedly to the disparity in scores of experience, and functional and professional expertise, as reflected in the form of variations in the level of general wisdom, and in the degree of flexibility and personal capabilities to bring about mutual understanding and interaction between workers of all levels horizontally and vertically, may lead to a kind of generational conflict within organizations. The organizations that took this issue a keen interest and designed work strategies, any organization is undoubtedly in desperate need for the elderly and their experience and wisdom, as it is in definite need for new generations and their knowledge, skills and enthusiasm, and thus become a required to paint scenarios needed to bring about integration and knowledge among all workers which have different ages.

Seventh:- Functional diversity itself; any organization has had the category of administrative or white collar stuff, also has executives and normal class workers or blue collar workers, there is no doubt that there is a significant gap or legal and psychological between these two categories, and should not be ignored, and the development of appropriate formalities, and appropriate guidance, to reduce its size and to avoid effects. (Wilson, 2014,68-74).Also up in the functional diversity among the category of managerial and professional category within organizations, and it's important to the organizations authorities realize the truth of that and its importance, and put all the formalities needed to bring interactive and complementary relationships between these groups and guidance. Administrators should realize the importance of technicians for the life of the organization, and they're part of an integral part, and they are the most important elements of the organization's success in its operations and to achieve its objectives. 
Technicians also must understand the role stature and importance of administrators who do all administrative arrangements that help technicians on their success, and that they (professionals). And do not aspire to administrative positions that if they have succeeded access to it, leading to disruption of artistic energies on the one hand, and they are not expected to succeed in their administrative roles because of the elements of personal and technical skills that they have differ from the administrative personal elements. (Worrel \& Cary, 2012.76-77) .As well as functional diversity among the category of managers and the category of experts and advisers, and the possibility of escalation of the conflict between them sometimes, this is reflected on the organization negatively. The organization responsible authority required to put the necessary regulatory scenarios for the development of each category in the proper context, so as to convince the advisers and experts that the work of administrative differs in terms of success on their work, and therefore, on these experts and consultants to focus on the tasks required of them in all honesty (consultant is - intimate), and does not aspire to management positions that may fail miserably if it were transferred to them. Well it is necessary to convince managers that they need the expertise of experts and advisers who are without their advice, and knowledge and experience; they may not be able to make decisions effectively.

Finally, functional diversity and differences between the Central upper levels of management and administrative levels and lower levels, this diversity may result in many organizations to the outbreak of the manifestations of hatred and personal intrigues, and manifestations of espionage and absent ... etc. Especially if there was a large and spacious gaps between the levels of compensation that workers get in each level of them.

The power authority in the organization should take care of this matter, and to estimated the severity of it, and put administrative and financial formalities necessary to minimize the negative effects and containment.

\section{8-2 the quality of work life:-}

It is not considered modern in the quality of work life or new in the management thought, and administrative practice, as some researchers may think, but it is due in fact to the model liberal-west in the mid-thirties of the last century with the surfacing of human relations school, and the escalation of this attention with the rise of behaviorism school in the fifties of the last century, which grows until it reached the limits of its peak following the emergence of Total quality management School at the beginning of the eighties of the last century, until now.

\section{The concept of quality of work life:-}

Regardless of any definitions may be presented by some scholars here or there, it could be argued that this concept of sufficient clarity that does not require to make hardship in order to identify the vocabulary of it, and if it was necessary to enter into this subject, it should be recognized that determining this concept needs to consider the following: (Wilson, 2014,86-87).

$>$ overview of all work life so that it is taking into account all the components of life, whether these components related to the internal environment of the organization, or affecting the external environment.

$>$ focus on quality necessary to improve all environmental components related to the life of the organization requirements, as a prerequisite to improve human resources in the organization, and make it truly the real capital in it.

Thus, the quality of life can be defined as the work situation which reflects the improvement or development of all elements of the organization and the foundations of all environments to ensure the provision to adapt the necessary atmosphere for human resources and resettlement in the organization, and to enable them to be the true capital of it.

\section{Core areas of working life:-}

Varied and multiple attention should be paid out to improve the lives of work in different organizations elements of the environment, and the most important thing that should be taken care of and focused on:

\section{Improve basic working conditions:-}

The basis for the improvement of the various working conditions on the demand aims at adapting the material elements of work with the needs of workers and material and moral circumstances and not vice versa. Dealing with the working conditions and development is supposed not to rely on the fact that workers are characterized by flexibility and speed of adaptation. But we must make the other elements are flexible and compatible with the requirements and expectations of employees and not inconsistent with them, and the most important conditions that must be observed. 
a. light intensity; It has been proved experimentally that the increase of light does not lead to increased productivity, and that there is a critical lighting degree of increase then stop point, this with the need to take into account individual differences among workers, some of whom needs severity of high illumination to works effectively, and some of them needs the intensity of lighting to be moderate, and so on ..., but the normal situation is that there are a critical lighting one minimum and the other is high point, and that productivity negatively affected if the degree of intensity of illumination less than the minimum, and it is fixed if above the maximum, it has been adversely affected in some exceptional cases. (Assaf, 2012,265-272)

b. Days and hours of work; (William Martar) conducting an experiment on the number of hours of work and its impact on productivity he found that the reduction of working hours has led to increased productivity and gave workers important opportunities for reflection and self-development and development of other work items. But reducing the number of weekly working days effect was present, but less degree of reduced working hours. (Assaf, 2012,267-274)

c. periods of daily comfort; experiments on the effects of rest periods has shown the importance of human relation during work, and the necessity of having breaks during work, it reactivates workers, whether their work that they carry out heavy and stressful, or boring and stressful psychologically. The breaks should not be multiple which leads to cutting business continuity and preparations for its implementation, and long breaks leads to inaction and lack of enthusiasm to return to work. (Morshal, 2012,56-65)

d. Ventilation, temperature, humidity and cold conditions noise and dust ... etc. All the factors that affect the impact, stressing the sense of working comfort and satisfaction, and it is a must for any organization that is keen to ensure the safety of its facilities and arrangements to have all this, in an effort to provide a good working environment as a requirement on one hand, and the demand for motivating employees and raise their performance levels on the other hand.

\section{Overcoming the problems:-}

Studies suggest that problems of work have a prominent role in the increase of accidents at work, says one study, $95 \%$ of work-related accidents were caused by human error, and 5\% were by machines, as was proven by the study that there is a relationship between the state of mental and physical of the worker and accidents before they happen. (Assaf, 2013), and the most important problems that can be referred to:

a. The problem of fatigue or stress; an experience shows that the patterns of social and psychological characteristics that could lead to stress and fatigue as the physical fatigue, studies have indicated that the cases of physical exhaustion less common in modern organizations than the psychological exhaustion. Some scholars say that the solution to fatigue problems do not have to remove fatigue completely by rest periods or other procedures within the organization, but to take the necessary steps to keep the fatigue at minimum before it happens, and this requires accurate studies, and the creation of appropriate working conditions.

b. the problem of boredom; some scholars believed that boredom is not as a result of physical causes, but rather is the result of psychological reasons, and occur as a result of fragmentation detailed work, which makes the worker feels futility and irrelevance, and leads him to boredom and then the physical and psychological stress.

c. To address the cases of boredom can change the work type of the employee from time to time, and develop a sense of the importance to the workers who do simple jobs and repetitive it is their roles that they do that make the organization to continue and elevate (Great job), as well as the development of the case of job stability, and granting appropriate wages, and to provide appropriate break periods, etc.

d. The problem of absenteeism and turnover work; highlights the absences as a problem when repeated markedly, and when top managers have doubts that absences did not have compelling excuse, but rather the negative feeling towards the business or organization.

e. One study has shown that rates of 25-33\% of absences due to neurotic diseases may be already exist among workers, and appeared while working out in unsuitable conditions, or as a result of the organization's policies concerning them. (Assaf, 2012,266-274)

f. The problem of incompatibility or functional adaptation; adaptation intended to find a balanced and acceptable relationship between workers and their work environment with all its components. The consensus is that each of the organization and employee convergence between each other to achieve a balance between their needs and objectives. It was the technological developments and its accelerated entry into the life of organizations, especially the computer revolution and related technical developments and administrative, which has a big impact and made a wide gap in the relations between workers and organizations, and vice versa, thereby exacerbating adjustment and functional compatibility issues needed and it is the most important thing to be 
recommended to provide an adequate amount of the balance of working and supporting the case of functional adaptation: (Parakash, 2015), (Wilson, 2014,112-116)

$>$ The development of the organization's preparations for compatibility with the interests of workers and their goals, and to highlight that in the rules and regulations prescribed by the management of their employees, and to develop policies and practices that actually confirms it.

$>$ Promote the spirit of social and collective solidarity with the workers through cultural and educational programs, and through some of the practices that are programmed for this purpose.

$>$ The design of technical programs for the use of computer systems and related support systems, skills, and educational and behavioral programs to promote new systems of relations between the workers themselves, and between them and the organization, in line with the imposed technological developments of relations.

$>$ Pursue advanced career and objective methods for selecting and directing careers, for the person who is chosen to work to be psychologically and professionally appropriate to the requirements of the work that he will exercise when his appointed.

$>$ Take into account individual differences among workers, and try to deal with all of them in accordance with the nature of his personality, and the system needs.

\section{Security management and occupational safety:-}

There is no disagreement about the concept of occupational safety and security, and it is known as expressing some most important areas which are looking at the ways to protect workers in the organizations in which they work for, from the effects resulting from all existing environment elements of each organization of risk factors mechanisms, and lead to health effects, directly or indirectly on the safety of workers and their health. This is in addition to the protection of the property of the various organizations, facilities, reputation and position in the market and society. (George \& Weimerskirch, 1998). It was the industrial revolution which caused the emergence of this issue to take its place and its importance, especially in the industrial organizations, which have many risks in the workplace, mechanical, electrical, chemical and physical, etc., which cannot be ignored by any organization or neglected, and it must manage it to ensure the provision of safe and healthy working environment. It is sufficient demonstration of the importance of this subject to the annual Statistics of the International Labor Organization (ILO) show that there are about 115 million workers in the world are exposed annually to accidents and injuries, of which about a variety of work (180000) injury leading to death. (AlAkailah, 2011,17-24). It was the first established law by the nations to protect the employees from the dangers of the environment of work is in Britain in (1802). The interest increased with the founding of the International Labor Organization at the end of the First World War, which became to take care of this matter. Then the formation of the Arab Labor Organization as one of the Arab League specialized organizations, issued Convention No. (7) of the occupational safety and health, and put obligations on the Arab countries in order to achieve protection for workers from exposure to any injuries of work or occupational diseases, as stipulated by the Convention No. 13; the need to improve the working conditions of physical, chemical and biological, technical and social .... (AlAkailah, 2011,16-29).Security management and safety functions: The main objective of this department is the protection of persons, individuals or groups, of any risks, which revolves around the functions of the department concerned, in addition to: (Sheraz, Salid, Quresh, \& Rizwan, 2014)

$>$ Protection of buildings, facilities and equipment and various equipment from the risk of damage or theft or other threats and risks.

$>$ Conservation and protection of raw materials during storage or use during the production process, as well as the conservation and protection of materials when processed and stored to avoid any potential risks.

$>$ Measuring the effects of all chemical and biological, electrical and lay the foundations for preventive basics, and build a foundation for complete information about all the environment of the organization, and to benefit from all of this in a safe and disciplined work environment, according to the required standards of prevention.

$>$ take care on the highest levels of mental health and physical and social, this requires the activation of legislation, regulations and procedures and technical and administrative arrangements in forced by the organization. And design training programs that build the skills of workers in the organization.

Organization environment risks: each organization is keen to be environment-friendly and all occupational safety and health conditions are secure, in order to avoid the most important risks: (Kakkos, 2011) (AlAkaileh, 2011,2654)

First, the physical hazards, including noise, humidity, ventilation, heat, cold, luminescent radiation and atmospheric pressure, and others. 
Second: chemical hazards, including the risk of toxic effects, and the effects of irritants or allergic or that which lead to distortions on birth or mind or otherwise.

Third: mechanical risks that come as a result of the wrong operation of machinery and equipment and various tools. Or as a result of error in carrying the loads and the method of downloading and others.

Fourth: the risks of construction, which relates to the fall of the materials or falling from scaffolding or cranes, or as a result of falling into the excavation or the result of some fires .. and so on.

Fifth: human risks, that stems from the weakness in some senses like smell or sight, or produced as a result of the psychological conditions of workers and their feelings of stress physical or moral, or the result of carelessness or negligence, and so on.

Sixth: the risks of mismatch between the employee and the work for any reason, which leads to the situations of stress and increase job errors and risks.

Seventh: biological risks: which result from the spread of harmful viruses and infectious bacteria, parasites and fungi.

Eighth: electrical hazards: caused by any errors in the use of machinery, equipment, fixtures, that uses electrical power.

The responsibility to improve security and safety conditions: the human resources management, in particular units responsible for the subject of security management and occupational safety, required to manage a system for the basic relations between all parties of the production processes in the organization in order to accomplish a number of important responsibilities, namely: (Ibrahim, 2014) (Kakkos, 2011)

1. The responsibility of the organization to develop an integrated and clear system of security and safety.

2. The responsibility of continuous coordination with the higher authorities in the organization, so as to develop the rules and regulations and issue decisions and instructions appropriate and necessary for their implementation.

3. Responsibility for coordination with suppliers, in order to determine where the source of the danger in all this, and what are the possibilities of the risks, and the preparation of evidence to show these things, and the definition of hazardous substances and their characteristics, the design of catalogs showing ways to use and contribute to the training of personnel on the use and operation. And determine what contingency plans in the event of a particular incident

4. Responsibility for coordination with the workers, so as to identify training needs of all equipment, tools and techniques used, and identify training plans aimed to explain to the workers the operating and maintenance details, and the development of operational skills, and familiarize them with the tools of prevention, systems and procedures. It is responsible for coordination with the various trade unions in order to approve the necessary protection systems for workers with all the details of that technical and procedural.

5. The responsibility of continuous coordination with the administrators of safety and security so as to ensure they are doing their duties in the best way possible, and to develop plans from their knowledge and skills.

Security and safety of workers system: There is no doubt that the protection of employees and providing good conditions for their security and safety, is one of the most important arrangements of any organization, and makes them at the head of the organizational and administrative priorities, and that their the absolute goal is to be zero accidents, because if any breaches of the cases of security or integrity happened, the results could be disastrous, notably: (Sing, 2011) (Parakash, 2015).

1. The humanitarian consequences that come as a result of injury to any of the workers with some work-related injuries that may cause him bodily harm leading to death or partial disability or permanent, which will reflect the occurrence of psychological and social effects on him or his family and relatives.

2. Social consequences for the society as a whole from some incidents of disabling some of the forces operating in it, and what consequences on their families from its effects.

3. The economic consequences of the organization as a result of any incidents that may be damaging to its assets or property or workers or the general population and the environment surrounding it. 
4. Legal consequences that may result if the argument broke out between the organization and employees affected or their families about their compensation for damages for their losses as a result of exposure to accidents at work, which is reflected on the reputation of the organization and its place in society.

That the organization must design an integrated system of security and safety which is one of the most important prerequisites that must be provided, and that the human resources management in the organization must working to verify the construction of this system, and discuss the elements and the specificity with the makers of the design mode. Security and safety system may differ from one organization to another depending on the nature of the work of each organization, its size, and its technologies. There is no doubt that the greater the technical nature of the Organization, and the Organization of substantial size, advanced technology, the degree of risk in it is high, security and safety system would grow more complex and important. Add to it that whenever there was high competition between the organization and some other organizations, the more job security considerations are needed, especially those related to information security and the protection of confidentiality. Ranging safety and security system components, according to the degree of complexity, and the areas it covers, and the most important thing we must focus on:

(A): The system vocabulary and the fields, the system should cover all aspects that could be breached more or less on the state of security and safety within the organization or outside, in particular the state of safety and security for their workers, or the people in the surrounding community, and the most important thing should be covered by the system namely: (AlAkaileh, 2011,55-155) (Siddique, Fatima \& Khan, 2013)

$>$ A comprehensive statement identifies all sources of risk, ranging from the highest sources of risk down to the least dangerous.

$>$ Build expectations of environmental risk sources, both with regard to the occurrence of earthquakes or floods, or other things that can happen and has an impact on the organization and its staff.

$>$ Determine the degree of risk entailed in each of these sources, and determine the risk involved in this, and affected stuff.

$>$ Identify the times that have higher degree of risk than others, and the system should identify a comprehensive disclosure list of all sources of danger and times of occurrence of each risk, and the degree of risk, according to each case, all the time.

$>$ Identify areas of risk within the organization, and draw a clear and comprehensive map showing all that, with the identification of risks for each place, and what is the degree of the risk.

$>$ Identify sources of external threats that are related to the organization, and determine the degree of seriousness of each of them, particularly as regards to opposition organizations, or the culture of the surrounding community and the likelihood of burglary, robbery or revenge and sabotage ... etc.

The system processes and procedures, which are carried out by the risk management within the organization and outside, and consists of two-fields: (Moshal, 2011,65-78) (ILO, 2014).

$>$ The first part: a precaution; includes all policies and regulations, tools and procedures that must be adhered to by the employees in the organization at all levels, and the most important as follows:

$>$ Build a comprehensive system of security and safety records include all incidents involving the organization, and what are the effects and results, to represent documentary reference which can be referred to it when necessary.

$>$ The design of criteria that include everything related to the general structure of the organization; electrical and mechanical systems, sewage networks, computer networks and systems. It also includes all the work of the organization and operations of every detail necessary to ensure the security and integrity of the organization and its staff and procedures.

$>$ The provision of supplies for the security and safety system, taking into account that they are consistent with the safety and security specific standards, with the need for continuous update.

$>$ Identify all the actions that are working out in case of any emergency, and circulated to all relevant personnel, and train them to do so in an orderly and accurate way, according to specified criteria.

$>$ Build a system for monitoring and inspection, which guarantees and ensures verification of compliance with all policies, standards and requirements and the specific arrangements and procedures.

$>$ Review of the items of the system as necessary to keep pace with the various developments. 
The second part: Therapeutic; in the event of danger for any reason, the security and safety system should include a comprehensive design and actions that must be taken to counter the threat and treatment and reduce its effects, and the most important thing must be contained in the system:

$>$ build your own risk occurrence of expectations, and its causes and degrees of damage that result from each of them, and a system of priorities for dealing with it.

$>$ Identify the arrangements and requirements and procedures that must be applied in every case of danger, and make sure that it is ready constantly.

$>$ Monitor a special budget (risk budget), so the organization will not find itself unable to finance any danger that it may be exposed to.

$>$ Conduct audits of vocabulary of the system and arrangements from time to time and again, and develop what needs to be developed, and add or delete what needs to be added or deleted.

The priorities of safety and security system; it includes priorities of following models; (Parakash, 2015).

First priority: The imminent risk, which confirms the high expectations on the probability of occurrence soon, if happened it will cause great harm to the organization or employees. And you must determine what these risks, and classifying them according to the degree of impact and the expected times of occurrence.

Second priority: large risks related to disasters and accidents that result in high-risk and negative results, determine what these risks are and classify them according to the degree of impact and the expected times of occurrence.

Third priority: the risks of non-compliance with the security standards and safety, or inputs, systems, regulations and technical and administrative specified procedures.

Fourth Priority: small risks relating to certain natural faults that are bound to occur in some of the equipment and techniques or electricity networks and various utilities.

Fourth Priority: The requirements for the system to succeed: it must provide a set of requirements that lead to the success of the system, at the corporate level or the staff level, or the surrounding environment and the surrounding community level. The most important of these requirements (Worral \& Cary, 2012,67-69):

$>$ That includes a comprehensive list of the most important reasons that could lead to an accidents or certain risk of the system, and work to develop solutions.

$>$ All levels of the organization's management should be committed to the system and conditions.

$>$ The training of all employees on the implementation of the system and all its standards, arrangements and procedures, and work to make the process of how to arrange of the applications in the event of any accident.

$>$ Identify and provide all the necessary requirements in the event of any accident, and to ensure availability and made available upon request at the time, and work to check it regularly.

$>$ To provide job security and safety nets, health insurance or social security, or the policies of job stability, and make sure they take into account the working conditions, according to each organization, and take into account the workers professional and living standards.

$>$ Design a code of honor to work, focusing on forbidding the abuse of drugs and alcohol and similar substances, and not to violate ethical norms accepted.

$>$ Comply with the regulations imposed by the trade unions technical and administrative.

The results of the study:-

First, it was a multiple linear correlation tests to ensure suitability of the study model, and the results were as follows:

Table 1:- multiple linear correlation test.

\begin{tabular}{|l|l|l|}
\hline Sequence & variation & VIF inflation rate variables \\
\hline 1 & diversity by gender & 2.767 \\
\hline 2 & diversity by age & 3.336 \\
\hline 3 & $\begin{array}{l}\text { diversity, according to functional category (administrators and } \\
\text { executives) }\end{array}$ & 2.155 \\
\hline 4 & $\begin{array}{l}\text { diversity, according to the functional level (senior management, } \\
\text { middle management and lower) }\end{array}$ & 1.988 \\
\hline
\end{tabular}


As noted, the results of each variation inflation is higher than one and less than ten, underscoring according to (Gujarati, 2004,352) there is no problem between the variables of the study.

Second:- A test of autocorrelation was conducted (Deran- Watson test) to ensure the absence of data from the autocorrelation problem, and the results were as follows:

Table 2:- autocorrelation test

\begin{tabular}{|c|c|c|c|c|}
\hline Hypothesis & $\begin{array}{c}\text { value }(\mathrm{D}-\mathrm{W}) \mathrm{d} \\
\text { calculated }\end{array}$ & $(\mathrm{dL})$ minimum & upper limits $(\mathrm{du})$ & result \\
\hline Ho1-1 & $1.8 \mathrm{o} 3$ & 1.758 & 1.779 & No self link \\
\hline Ho1-2 & 1.812 & 1.758 & 1.779 & No self link \\
\hline Ho1-3 & 1.852 & 1.758 & 1.779 & No self link \\
\hline Ho1-4 & 1.905 & 1.758 & 1.779 & No self link \\
\hline Ho1 & 1.889 & 1.728 & 1.809 & No self link \\
\hline
\end{tabular}

As can be seen, all the values of (d) outside the limits specified in the standard values (dL), In (du), which confirms the absence of evidence of autocorrelation and validity problem in the use of the regression model.

Third:- hypotheses test; was conducted by analyzing the simple linear regression and gradual, and the results were as follows:

(1) test the first sub-hypothesis (H01-1), and the result was as follows in Table (3)

Table 3:- impact test results by age diversity on the quality of working life

\begin{tabular}{|c|c|c|c|c|c|c|c|c|c|c|}
\hline \multicolumn{5}{|c|}{ Coefficient } & \multicolumn{3}{|c|}{ ANOVA } & \multicolumn{2}{|c|}{$\begin{array}{c}\text { Model } \\
\text { Summery }\end{array}$} & \multirow{2}{*}{$\begin{array}{c}\text { I The } \\
\text { depende } \\
\text { nt } \\
\text { variable }\end{array}$} \\
\hline $\begin{array}{l}\text { Sig t } \\
\text { level of } \\
\text { significan } \\
\text { ce }\end{array}$ & $\begin{array}{l}\mathbf{T} \\
\text { calculate } \\
\text { d }\end{array}$ & $\begin{array}{l}\text { standar } \\
\text { d error }\end{array}$ & B & statement & $\begin{array}{c}\text { Sig } \\
\text { F }\end{array}$ & $\begin{array}{c}\text { Df } \\
\text { degree } \\
\text { of } \\
\text { freedo } \\
\text { m }\end{array}$ & $\begin{array}{c}\mathbf{F} \\
\text { calculate } \\
\mathrm{d}\end{array}$ & $\mathbf{r}^{2}$ & $\begin{array}{c}\mathbf{R} \\
\text { correlatio } \\
\mathrm{n} \\
\text { coefficie } \\
\mathrm{nt}\end{array}$ & \\
\hline 0.000 & 14.763 & 0.038 & $\begin{array}{l}0.56 \\
7\end{array}$ & $\begin{array}{c}\text { polarizatio } \\
n\end{array}$ & $\begin{array}{c}0.00 \\
0\end{array}$ & 1 & 217.945 & $\begin{array}{c}0.47 \\
9\end{array}$ & 0.692 & $\begin{array}{c}\text { quality } \\
\text { of work } \\
\text { life }\end{array}$ \\
\hline
\end{tabular}

As can be seen, the value of the correlation coefficient (r) between the diversity variable by gender and variable quality of work life is positive, high-value, according to the standard (Zikmund, 2000, 513) as can be seen that, the coefficient of determination (r2) has interpreted the role of the state of diversity by gender in the level of variation $(47.9 \%)$, with all other variables remain constant. Also, the value of $(F)$ has confirmed a significant gradient at the level of less than $5 \%$, at a confidence level $(\mathrm{Sig}=0.000)$, as well as the rest of the results confirm a significant coefficient at least 5\%, and this leads to the rejection of the hypothesis Sub-first, and to accept the hypothesis (that there is a statistically significant effect in the abstract level of equal to or less than $5 \%$ of the state of diversity by gender on the quality of working life of the system in the Jordan Islamic Bank). (2) The second sub-test the hypothesis (H01-2), and the result was as follows in Table (4)

Table 4:- impact test case diversity results by age on the quality of working life of the system.

\begin{tabular}{|c|c|c|c|c|c|c|c|c|c|c|}
\hline \multicolumn{5}{|l|}{ Coefficient } & \multicolumn{3}{|c|}{ ANOVA } & \multicolumn{2}{|c|}{$\begin{array}{l}\text { Model } \\
\text { Summery }\end{array}$} & \multirow{2}{*}{$\begin{array}{l}\text { The } \\
\text { depende } \\
\text { nt } \\
\text { variable }\end{array}$} \\
\hline $\begin{array}{l}\text { Sig t } \\
\text { level of } \\
\text { significan } \\
\text { ce }\end{array}$ & $\begin{array}{l}\mathbf{T} \\
\text { calculate } \\
\mathrm{d}\end{array}$ & $\begin{array}{l}\text { standar } \\
\text { d error }\end{array}$ & $\mathbf{B}$ & statement & $\begin{array}{l}\text { Sig } \\
\text { F }\end{array}$ & $\begin{array}{l}\text { Df } \\
\text { degree } \\
\text { of } \\
\text { freedo } \\
\mathrm{m}\end{array}$ & $\begin{array}{l}\mathbf{F} \\
\text { calculate } \\
\text { d }\end{array}$ & $\mathbf{r}^{2}$ & $\begin{array}{l}\mathbf{r} \\
\text { correlatio } \\
\mathrm{n} \\
\text { coefficie } \\
\mathrm{nt}\end{array}$ & \\
\hline 0.000 & 16.496 & 0.036 & $\begin{array}{l}0.59 \\
5\end{array}$ & $\begin{array}{l}\text { resettleme } \\
\mathrm{nt}\end{array}$ & $\begin{array}{l}0.00 \\
0\end{array}$ & 1 & 272.123 & $\begin{array}{l}0.53 \\
4\end{array}$ & 0.731 & $\begin{array}{l}\text { Quality } \\
\text { of work } \\
\text { life of } \\
\text { the } \\
\text { system }\end{array}$ \\
\hline
\end{tabular}


As can be seen, the value of the correlation coefficient ( $r$ ) between the state of diversity variable by age and variable quality of work life is (73.1\%), a positive, high-value, according to the standard (Zikmund, 2000, 513) as can be seen that the coefficient of determination $(\mathrm{r} 2)$ has interpreted the role of the state of diversity by age in the quality of work life standard amount of variation of 53.4\%, with all other variables remain constant. Also, the value of (F) has confirmed a significant gradient at the level of less than 5\%, at a confidence level ( $\mathrm{Sig}=0.000)$, as well as the rest of the results a significant coefficient at least 5\%, and this leads to the rejection of the hypothesis sub-second, and to accept the hypothesis (that there is a statistically significant effect in the abstract level of equal to or less than $5 \%$ of the state of diversity, according to a variable-age on the quality of working life of the system in the Jordan Islamic Bank).

(3) Test the hypothesis Sub-third (H01-3), and the result was as follows in Table (5)..

Table 5:- the impact of the test case of diversity, according to the results of the functional groups on the quality of working life of the system:

\begin{tabular}{|l|l|l|l|l|l|l|l|l|l|}
\hline \multicolumn{2}{|l|}{ Coefficient } & \multicolumn{2}{l|}{ ANOVA } & \multicolumn{2}{l|}{$\begin{array}{l}\text { Model } \\
\text { Summery }\end{array}$} \\
\hline $\begin{array}{l}\text { Sig t } \\
\text { level of } \\
\text { significanc } \\
\text { e }\end{array}$ & $\begin{array}{l}\text { T } \\
\text { calculate } \\
\text { d }\end{array}$ & $\begin{array}{l}\text { standar } \\
\text { d error } \\
\text { depende } \\
\text { nt } \\
\text { variable }\end{array}$ \\
\end{tabular}

As can be seen, the value of the correlation coefficient ( $r$ ) between the state of diversity variable depending on the functional groups on the quality of work life is a system (72.1\%), which is a positive, high-value, according to the standard (Zikmund, 2000,513) as can be seen that the coefficient of determination (r2) may be interpreted the role of the state of diversity, according to categories of staff in the quality of working life system, standard amount of variation $(50.7 \%)$, with all other variables remain constant. Also, the value of (F) has confirmed a significant gradient at the level of less than $5 \%$, at a confidence level $(\mathrm{Sig}=0.000)$, as well as the rest of the results confirm a significant coefficient at least $5 \%$, and this leads to the rejection of the hypothesis Sub-third, and to accept the hypothesis (that there is a statistically significant effect in the abstract level of equal to or less than 5\% of the state of diversity, according to the functional groups on the quality of working life of the system in the Jordan Islamic Bank).

(4) Test the hypothesis Sub-fourth (H01-4), and the result was as follows in Table (6).

Table 6:- the impact of the test case of diversity, according to the results of the functional level on the quality of working life of the system.

\begin{tabular}{|c|c|c|c|c|c|c|c|c|c|c|}
\hline \multicolumn{5}{|l|}{ Coefficient } & \multicolumn{3}{|c|}{ ANOVA } & \multicolumn{2}{|c|}{$\begin{array}{l}\text { Model } \\
\text { Summery }\end{array}$} & \multirow{2}{*}{$\begin{array}{l}\text { The } \\
\text { depende } \\
\text { nt } \\
\text { variable }\end{array}$} \\
\hline $\begin{array}{l}\text { Sig t } \\
\text { level of } \\
\text { significan } \\
\text { ce }\end{array}$ & $\begin{array}{l}\mathbf{T} \\
\text { calculate } \\
\mathrm{d}\end{array}$ & $\begin{array}{l}\text { standar } \\
\text { d error }\end{array}$ & B & statement & $\begin{array}{l}\text { Sig } \\
\text { F }\end{array}$ & $\begin{array}{l}\text { Df } \\
\text { degree } \\
\text { of } \\
\text { freedom }\end{array}$ & $\begin{array}{l}\mathbf{F} \\
\text { calculat } \\
\text { ed }\end{array}$ & $\mathbf{r}^{2}$ & $\begin{array}{l}\mathbf{r} \\
\text { correlatio } \\
\mathrm{n} \\
\text { coefficie } \\
\mathrm{nt}\end{array}$ & \\
\hline 0.000 & 17.032 & 0.037 & $\begin{array}{l}0.63 \\
9\end{array}$ & $\begin{array}{l}\text { preservatio } \\
\mathrm{n}\end{array}$ & $\begin{array}{l}0.00 \\
0\end{array}$ & 1 & $\begin{array}{l}290.08 \\
7\end{array}$ & $\begin{array}{l}0.55 \\
0\end{array}$ & 0.742 & $\begin{array}{l}\text { Quality } \\
\text { of work } \\
\text { life } \\
\text { system }\end{array}$ \\
\hline
\end{tabular}

As can be seen, the value of the correlation coefficient (r) between the state of diversity variable depending on the functional level and the variable quality of work life in a system (74.2\%), which is a positive, high-value, according to the standard (Zikmund, 2000,513) as can be seen that the coefficient of determination (r2) may be interpreted the 
role of functional diversity, according to the functional level in the quality of work life of the level of $\$ 55.0 \%$ variation, with all other variables remain constant. Also, the value of $(\mathrm{F})$ has confirmed a significant gradient at the level of less than $5 \%$, at a confidence level ( $\mathrm{Sig}=0.000)$, as well as the rest of the results confirm a significant coefficient at least 5\%, and this leads to the rejection of the hypothesis Sub-fourth, and to accept the hypothesis to become (that there is a statistically significant effect in the abstract level of equal to or less than 5\% of diversity, according to the functional level on the quality of working life of the system in the Jordan Islamic Bank).

(5) test the hypothesis President, and to identify any of the sub-variables most impact in the quality of life of work system, and has been so for a multi-tiered regression testing, the following table illustrates this:

Table 7:- a summary of the model to test the main hypothesis.

\begin{tabular}{|c|c|c|c|c|c|}
\hline \multicolumn{5}{|c|}{ Model summary form } & \multirow[t]{2}{*}{ Model } \\
\hline $\begin{array}{l}\text { coefficient } \\
\text { determination }\end{array}$ & $\begin{array}{r}\text { of } \\
\text { standard } \\
\text { error }\end{array}$ & & $\begin{array}{c}\text { coefficient of } \\
\text { determination }\end{array}$ & $\begin{array}{c}\mathbf{R} \\
\text { correlation coefficient }\end{array}$ & \\
\hline & 0.504 & & 0.550 & 0.742 & 1 \\
\hline & 0.435 & & 0.667 & 0.817 & 2 \\
\hline & 0.416 & & 0.697 & $\mathbf{0 . 8 3 5}$ & 3 \\
\hline & 0.409 & & 0.707 & 0.841 & 4 \\
\hline
\end{tabular}

Table 8:- analysis of variance to test the main hypothesis.

\begin{tabular}{|c|c|c|c|c|c|}
\hline $\begin{array}{c}\text { Sig F } \\
\text { level of } \\
\text { significance }\end{array}$ & $\begin{array}{c}\mathbf{F} \\
\text { calculated }\end{array}$ & $\begin{array}{c}\text { D f } \\
\text { degree of } \\
\text { freedom }\end{array}$ & sum of squares & mo & \\
\hline \multirow[t]{3}{*}{0.000} & \multirow[t]{3}{*}{290.087} & 1 & 73.682 & Regression & \multirow[t]{3}{*}{1} \\
\hline & & 237 & 60.198 & Residual & \\
\hline & & 238 & 133.880 & Total & \\
\hline \multirow[t]{3}{*}{0.000} & \multirow[t]{3}{*}{236.138} & 2 & 89.270 & Regression & \multirow[t]{3}{*}{2} \\
\hline & & 236 & 44.609 & Residual & \\
\hline & & 238 & 133.880 & Total & \\
\hline \multirow[t]{3}{*}{0.000} & \multirow[t]{3}{*}{179.769} & 3 & 93.247 & Regression & \multirow[t]{3}{*}{3} \\
\hline & & 235 & 40.632 & Residual & \\
\hline & & 238 & 133.880 & Total & \\
\hline \multirow[t]{3}{*}{0.000} & \multirow[t]{3}{*}{141.181} & 4 & 94.657 & Regression & \multirow{3}{*}{4} \\
\hline & & 234 & 39.222 & Residual & \\
\hline & & 238 & $\mathbf{1 3 3 . 8 8 0}$ & Total & \\
\hline
\end{tabular}

Note that the data in Table 7 shows that the first model for gradual regression analysis shows that diversity variable is depending on the functional level and may be interpreted accounted for 55\% of the total variation in the quality of work life, and become ratio 66.7 when you add diversity variable by age to diversity variable depending on the functional level, the ratio becomes 69.7 when you add diversity to a business class, for up to 70.7 by adding diversity by gender. While noting that the value of the levels (F) in all the different models within the abstract level $(\mathrm{Sig}=0.000)$ as shown in Table (9) as follows:

Table 9:- the results of regression coefficient is a summary to test the main hypothesis

\begin{tabular}{|c|c|c|c|c|c|}
\hline $\begin{array}{l}\text { Sig } \\
\text { significance } \\
\text { level }\end{array}$ & $\begin{array}{ll}\mathbf{t} & \text { calculated } \\
\text { value } & \end{array}$ & Std.Error & B & quality work life & Model \\
\hline 0.000 & 17.032 & 0.037 & 0.639 & $\begin{array}{l}\text { diversity, } \\
\text { according to the } \\
\text { functional }\end{array}$ & First \\
\hline 0.000 & 9.680 & 0.042 & 0.402 & $\begin{array}{l}\text { diversity, } \\
\text { according to the } \\
\text { functional }\end{array}$ & \multirow[t]{2}{*}{ Second } \\
\hline 0.000 & 9.081 & 0.039 & 0.357 & Diversity by age & \\
\hline 0.000 & 7.795 & 0.042 & 0.331 & $\begin{array}{l}\text { diversity, } \\
\text { according to the }\end{array}$ & Third \\
\hline
\end{tabular}




\begin{tabular}{|l|l|l|l|l|l|}
\hline & & & & functional & \\
\hline $\mathbf{0 . 0 0 0}$ & $\mathbf{6 . 0 1 3}$ & $\mathbf{0 . 0 4 3}$ & $\mathbf{0 . 2 5 8}$ & Diversity by age \\
\hline $\mathbf{0 . 0 0 0}$ & $\mathbf{4 . 7 9 6}$ & $\mathbf{0 . 0 4 1}$ & $\mathbf{0 . 1 9 4}$ & $\begin{array}{l}\text { Diversity, } \\
\text { according to the } \\
\text { functional level }\end{array}$ & \\
\hline $\mathbf{0 . 0 0 0}$ & $\mathbf{7 . 0 2 0}$ & $\mathbf{0 . 0 4 3}$ & $\mathbf{0 . 3 0 2}$ & $\begin{array}{l}\text { diversity, } \\
\text { according to the } \\
\text { functional }\end{array}$ & Fourth \\
\hline $\mathbf{0 . 0 0 2}$ & $\mathbf{3 . 1 6 7}$ & $\mathbf{0 . 0 5 3}$ & $\mathbf{0 . 1 6 7}$ & Diversity by age \\
\hline $\mathbf{0 . 0 0 0}$ & $\mathbf{4 . 8 5 1}$ & $\mathbf{0 . 0 4 0}$ & $\mathbf{0 . 1 9 4}$ & $\begin{array}{l}\text { Diversity, } \\
\text { according to the } \\
\text { functional level }\end{array}$ & \\
\hline $\mathbf{0 . 0 0 4}$ & $\mathbf{2 . 9 0 0}$ & $\mathbf{0 . 0 4 8}$ & $\mathbf{0 . 1 4 0}$ & $\begin{array}{l}\text { Diversity by } \\
\text { gender }\end{array}$ \\
\hline
\end{tabular}

By observing these results, we find that the values of (B) in the two models at levels ( $\mathrm{t}$ ) is different at the significance level $(\mathrm{Sig}=0.004)$ or less, and this confirms a significant regression co-efficients, which confirms that the impact of these variables in the models statistically significant. Accordingly, we reject the premise of it and accept the alternative hypothesis that (There is no impact statistically significant at a moral level $\mathrm{P} \leq 0.05$ cases diversity of different dimensions (gender, age and job category, career level) on the quality of working life of the system in terms of its various dimensions (working conditions and labor problems and the system of Security and safety) in the Jordan Islamic Bank.

\section{References:-}

1. A-A kaili, An Environment of Work:Risks and Protection Criteria,Amman,2011

2. Assaf,abdulmoti, Organizational Behavior, Amman,Dar-Zahran,2012

3. Chuai,Xin,Preece,David \&,Iles.PaulIs Talent Management Just Old Wine in New Bottle?, The Case of Multinational Companies in Beiging, Management Research News,31(12),85-96,2008

4. Gujarati,Damodar,NBasic Econometrics, $4^{\text {th }}$ ed. New York,The McGraw-Hill Co.2004

5. Gunalu,Ebru,Mhmet,Aksarayali\&Nilufer Sahin,Job Satisfaction and Organizational Commitment of Hotel Managers in Turkey,International Journal of Contemporary Hospitality Management,22(5)pp693-717,2010

6. Ibrahim, H.,The relationship between job stress, co-worker support and organization-bases self-esteem: a survey across different occupations. Journal of Arts, Science\&Commerce, 1(2) ,69-78.,2014

7. Ichi,Shin Takezawa\&Arthur,M.,Whitehill,WorkWays :Japan And America ,The Japanese Institute of Labour.1984

8. ILO,Yearbook of Labour Statistics, Geneva,Vol.2014

9. Kakkos N., Trivellas P. Investigating the Link Between Motivation, Work Stress and Job Performance. Evidence From the Banking Industry. $8^{\text {th }}$ International conference on enterprise systems, Accounting and logistics ( $8^{\text {th }}$ ICESAL' 11) , 408- 428, 2011

10. Kehinde,James, Talent Management-Effect on Organizational Performance,Lagos State University,Nigeria West Africa, Journal of Management research,4(2)146-158,2012

11. Moshal B.S.Organizational Theory and Behavior(3 ed). New delhi, Parwana Bhawan: Ane Books pvt.ltd,2012

12. Nasyira,M.N.,Othman,M.N.,\&Gazali,H,Predictors of Intention to Stay for Employees of Casual Dining Restaurant in Klang Valley area ,International Food Research Journal,26-45,2014

13. Noori,M.,\&Bezanaj,A.A.M.Talent Management Strategy in Iranian Private Sector Banking Strategic, Interdisciplinary Journal of Contemporary Research in Business,5(4),220-234,2013

14. Parakash P. To study employee motivational factors influencing managerial behavior .International Journal of Research,2(2),360-365.2015

15. Polk,William,(ed.),Development Revelution,North Africa,Middle East,\&Asia,Washington,D,C.2011

16. Richard,E.Boyatzis, Competencies in the $\mathbf{2 1}^{\text {st }}$ Century ,Journal of management Development,27(1),5-12,2008

17. Sail,Rahim,\&Alavi,Khadijah,Social Skills and Social Values,Journalof European Industrial Training,Emerald Group,34(3),226-258,2010

18. http://www.samtah.net/vb/showthread.php/124688 
19. Sheraz A., Wajid M., Sajid M., Qureshi w., \& Rizwan m., Antecedents of job Stress and its impact on employees job satisfaction and Turnover intentions. International Journal of Learning \& Development, 4(2), 204- 226. 2014

20. Siddique Z., Fatima M., Mohd H., \& Khan I., The impact of social and family role stress on the achievement motivation of Indian teachers. Malaysian Journal of Society and Space, 9(2), 12-2 8.2013

21. Sing,Narendar, Human Resource Management,New Delhi University of Science Press.2011

22. Wallgren N.,Motivation Requested Work Motivation and the Work Environment of IT Consultants, Doctoral dissertation, university of Gothenburg, Gothenburg, Swede,2011

23. Suhasini,N.Naresh Babu,T.,Retention Management; A Strategic Dimension of Indian IT Companies, International Journal of Management and Social Sciences Research,2(2),2319-2331,2013

24. Wilson,John,P. International Human Resource Development Learning,Education,and Training for Individuals and Organizations, Glasgow,Bell\&bain ,Ltd.2014

25. Worral,Les, \&Cooper,Cary,Quality of Working Life Manager,Wellbeing,Motivation\&Productivity,2012

26. Zikmund,William,G.,BusinessResearch Methods, $6^{\text {th }}$ ed.,Fort Worth:Harcourt College Publishers, 2000 